\title{
The Diminishing Returns to the 2010 Human Development Index: Implications for Climate Policy and Sustainable Development
}

\author{
Susan G. Spierre ${ }^{1}$, Thomas P. Seager ${ }^{2} \&$ Evan Selinger $^{3}$ \\ ${ }^{1}$ School of Sustainability, Arizona State University, Tempe, AZ, USA \\ ${ }^{2}$ School of Sustainable Engineering and the Built Environment, Arizona State University, Tempe, AZ, USA \\ ${ }^{3}$ Department of Philosophy, Rochester Institute of Technology, Rochester, NY, USA \\ Correspondence: Susan G. Spierre, School of Sustainability, Arizona State University, Tempe, AZ, USA. E-mail: \\ susan.spierre@asu.edu
}

Received: February 19, 2013 Accepted: May 8, 2013 Online Published: May 14, 2013

doi:10.5539/jsd.v6n6p34 URL: http://dx.doi.org/10.5539/jsd.v6n6p34

\begin{abstract}
Human development, energy, and greenhouse gases are inherently linked under current technology constraints. An empirical comparison illustrates that nations with higher human development values (in terms of the United Nation's Human Development Index (HDI)) contribute more carbon dioxide $\left(\mathrm{CO}_{2}\right)$ emissions as a result of greater energy consumption. This finding seemingly places environmental sustainability at odds with advances in human development. However, the comparison also exposes the diminishing returns to HDI that accrue as emissions increase. If accurate, this relationship suggests that the developed world can make emission cuts without experiencing major set-backs in human well-being. It also suggests that under a global mitigation system, emission cuts in developed nations could enable emission increases in underdeveloped countries that result in major improvements to the human condition. Therefore, we investigate the diminishing returns to HDI in the context of sustainable climate policy design. We find that the saturation-like trend is inherent to development indicators and not driven by the functional form of the HDI. Also, the global trend is not consistently detected when the development pathways of individual nations are examined. Nevertheless, a clear relationship between $\mathrm{CO}_{2}$ and $\mathrm{HDI}$ emerges within the least developed nations, fourteen of which show consistent advances in HDI as emissions increase over time. These findings suggest that sustainable climate policy should not allocate emission rights away from these nations. Furthermore, most developed nations exhibit periods of HDI improvement while emissions decline, reinforcing the criticality of employing broader development measures beyond indicators of income for sustainable policy design.
\end{abstract}

Keywords: human development, diminishing returns, climate policy, energy, climate change, HDI

\section{Introduction}

\subsection{The Energy-CO $\mathrm{C}_{2}$-Development Nexus}

It is undeniable that energy is fundamental for human development. The exploitation of inexpensive fossil fuels has historically been the foundation of the industrial and agricultural revolutions, which enabled remarkable increases in the standard of living for hundreds of millions people. On the other hand, countries with poor access to modern energy resources remain in poverty; over 1.6 billion people (almost one third of humanity) have no electricity and consequently lack essential energy services for schools, health centers and income generation (Birol, 2007). In fact, no country consuming the energy equivalent to $750 \mathrm{~kg}$ of oil per year per capita achieves an average life expectancy of over 75 years (World Bank, 2011).

However, energy has a down-side under current technology constraints. The combustion of fossil fuels for energy production is the primary source of harmful greenhouse gas (GHG) emissions contributing to climate change (Barker et al., 2007). Also, it will be at least several decades before renewable-energy industries can substantially replace oil, coal, and natural gas energy sources (Ayres \& Ayres, 2010). A further complication is that the inequities of how energy is consumed globally translate into differentiating responsibilities for contributing to global warming. In 2004, developed countries (Annex I countries under Kyoto) had $20 \%$ of the world's population, but accounted for $46 \%$ of global GHG emissions. On the other hand, $80 \%$ of the population living in developing nations (non-Annex I countries under Kyoto) emitted 54\% (Barker et al., 2007). In terms of regional per capita 
emissions, the difference is even more pronounced; The US and Canada are home to 5.0\% of the population and emits $19.4 \%$ of GHG emissions, while $30.3 \%$ of the population in South Asia emits just $13.1 \%$ (Barker et al., 2007).

The deleterious effects of climate change, resulting from GHG emissions, are also likely to be heterogeneous. Some regions will experience significant negative effects such the loss of life and property due to sea level rise, climate extremes, loss of agricultural productivity, and damage to infrastructure from the melting of permafrost and/or more frequent extreme weather events. Others may experience minor negative effects or successfully adapt to changing environmental conditions. Lastly, certain countries (such as Russia and Canada) may experience net benefits such as lower winter heating costs due to warmer temperatures, a longer agricultural growing season, increased forest productivity, or an expansion of tourism due to land use changes (UNDP, 2007). These inequalities in impact and adaptive capabilities suggest that global climate change is likely to create both winners and losers (Tol, 2009). Under any climate scenario, the poorest individuals will likely suffer the most. Underdeveloped countries that have contributed minimally to the problem are already suffering from rising temperatures (e.g., from sea-level rise and/or agricultural setbacks), and typically lack the ability to adapt in terms of things like financial resources, poor infrastructure, and weak institutions (O'Brien \& Leichenko, 2006).

Consequently, there is an inequitable distribution of the benefits as well as damages associated with energy consumption and anthropogenic climate change. An empirical comparison between a nation's human development level (according to the United Nations Human Development Index or HDI) and per capita carbon dioxide $\left(\mathrm{CO}_{2}\right)$ emissions (we look particularly at consumption-based emissions; reasons for this provided in the next section) shows a clear correlation: nations with higher per capita $\mathrm{CO}_{2}$ emissions exhibit greater achievements in human development (Figure 1). However, the comparison also reveals the diminishing returns to HDI as nations transition to higher level of per capita emissions (indicated by the regression of the data in Figure 1). This relationship is also referred to as "plateau" by Pasternak (2000) or "saturation" by Martinez and Ebenhack (2008).

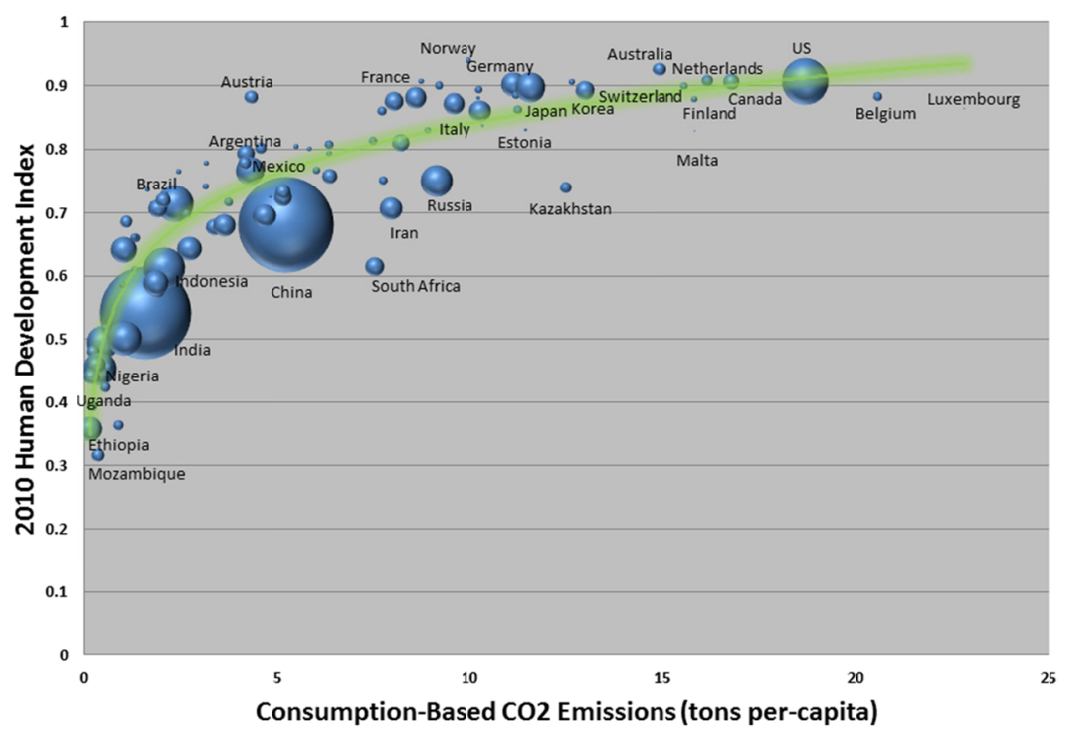

Figure 1. Comparison between consumption-based per capita emissions (includes emissions transfers from international trade) and HDI by country in 2010. The size of the bubbles indicates each country's relative population. Select countries are labeled. Singapore is excluded from the figure due to its very high per capita emissions (48 tons per capita and HDI of 0.864). The green trend-line is the logarithmic regression of the data with an $R^{2}$ value of 0.845 (the closer the $R^{2}$ value is to 1 , the better the fit)

We hypothesize that the diminishing returns we observe in Figure 1 is an artifact of human well-being indicators (such as proxies for health and education) becoming less dependent on energy and carbon as nations develop. If accurate, the implication is that emission reductions on the part of the developed countries may not mean significant sacrifices to human well-being. Furthermore, the figure suggests that under global $\mathrm{CO}_{2}$ limits (e.g., to keep temperature increases below $2{ }^{\circ} \mathrm{C}$ ) emission reductions by developed countries could enable major 
improvements in the quality of life for individuals within the world's least developed nations. Thus climate policy and sustainable development, i.e., development that gives priority to the needs of the poor and recognizes the limitations of the environment's ability to support humanity (United Nations, 1987), are inherently interrelated; efforts to address one without considerations of the other will likely be unsuccessful (Beg et al., 2002; Swart, Robison, \& Cohen, 2003). This research therefore explores the relationship between per capita $\mathrm{CO}_{2}$ emissions and the observed diminishing returns to HDI in many countries to clarify its implications for sustainable global climate policy.

\subsection{Literature Review}

The diminishing returns to HDI when compared with energy and/or $\mathrm{CO}_{2}$ emissions have been identified previously. For example, Pasternak (2000) examined the relationship between HDI and per capita electricity consumption for 60 countries and estimated the electricity consumption needed to bring all countries to the 4,000 $\mathrm{kWh}$ per year level, the threshold for achieving an HDI of 0.9 or greater in 1997. Martinez and Ebenhack (2008) showed that the diminishing return to HDI from per capita energy consumption for 120 countries was stronger when major energy exporting countries (e.g., OPEC nations) were filtered out. Also, Mechtenberg et al. (2012) found that human development is exponentially related to electricity consumption and uses the relationship to identify nations with low HDI that may benefit from human powered electricity generation. However, what these authors fail to elucidate is how the aggregation of the data included in the HDI influences the relationship they observe. That is, the methodology used to aggregate diverse data-sets (e.g., with different units and distinct ranges) may oversimplify or exaggerate important aspects of data, thereby potentially misleading decision-makers (Prado, Rogers, \& Seager, 2012).

Moreover, there is a paucity of information on how the relationship between HDI and energy or $\mathrm{CO}_{2}$ indicators changes over time. In a few instances, authors have compared an early data set (circa 1960's \& 1970's) to more recently reported data (1990's and early 2000's), noting improvements in the HDI attainable at different levels of energy (Suarez, 1995; Pasternak, 2000). Also, HDI and ecological footprint were found to increase together when country-level data for both indicators are contrasted for the years 1975 and 2003 (Moran, Wackernagel, Kitzes, Golfinger, \& Boutaud, 2008). There are, however, only two studies (by the same lead author) that consider changes in HDI for more than two points in time (necessary to observe the saturation-like effect). One study computed regressions for HDI versus per capita primary energy at the aggregate level (for 80 countries) and territorial based carbon emissions data (for 93 countries) from 1975 to 2005 (Steinberger \& Roberts, 2010). They found that HDI levels were achieved at decreasing levels of energy and carbon emissions over time and show the differences in energy/carbon trends with increasing HDI for six select countries over the same time period. A more recent study compared both energy and carbon emissions to human development indicators (life expectancy and GDP) for many countries in 2004. The diversity in development trajectories of thirteen select nations was also shown. One of the key findings was that high life expectancy can be achieved at a large range of carbon emission levels, whereas income is much more closely linked with carbon. This is an important finding, as it suggests that mitigation on the part of the developed nations, even if it negatively impacts income, does not necessarily mean significant costs to non-income components of human well-being (Steinberger, Roberts, Peters, \& Baiocchi, 2012). This latter study, in particular, emphasizes the criticality of considering broader measures of development, beyond measures of income, when assessing sustainable climate policy.

\subsection{Research Objectives}

The key point is that the relationship between $\mathrm{CO}_{2}$ and human development has critical implications for global climate policy. If $\mathrm{CO}_{2}$ is a necessary component for human development advances, than sustainable climate policy would include mechanisms that protect the minimum amount of $\mathrm{CO}_{2}$ needed for sufficient development. This research seeks to clarify this relationship further in two specific ways. First, we investigate the 2010 HDI methodology to determine how the index calculation influences the diminishing returns to $\mathrm{HDI}$ as per capita $\mathrm{CO}_{2}$ emissions increase. This will elucidate how valuable the HDI is in terms of informing sustainable climate policy. Second, we examine individual development pathways of countries from 1990-2010 to determine if the diminishing returns to HDI we observe at the global level is also exhibited by individual countries, as their consumption-based per capita $\mathrm{CO}_{2}$ emissions increase over time. Studying the distinct development pathways of nations compared to their $\mathrm{CO}_{2}$ emissions is important to assess the implications of mitigation efforts on country-level human development.

\section{Method}

Taking a systems approach to the sustainability issues of climate change and sustainable development require considerations of economic, social and environmental aspects of these challenges. Our investigation is therefore 
designed to include indicators for each sustainability pillar. The environmental pillar is reflected in our independent variable: consumption-based $\mathrm{CO}_{2}$ emissions per capita. The economic and social dimensions are represented via indicators within the HDI, our dependent variable. In this section we describe the reasons for using these particular variables for this research.

\subsection{Independent Variable: Consumption-Based Per Capita $\mathrm{CO}_{2}$ Emissions}

Under the Intergovernmental Panel on Climate Change (IPCC) accounting rules, mitigation only applies to "greenhouse gas emissions and removals taking place within national territory and offshore areas over which the country has jurisdiction", also known as a country's territorial emissions (IPCC, 2008). The problem is that inventories of territorial emissions do not include life-cycle considerations. That is, it assigns the carbon-dioxide of goods produced for export to the producing countries (i.e., the exporters), rather than the consuming countries (i.e., the importers). Consequently, results indicate that $\mathrm{CO}_{2}$ emissions in developed nations have generally stabilized, while emissions from developing nations have about doubled since 1990 (Le Quéré et al., 2009).

Alternatively, Peters, Mix, Weber, and Edenhofer (2011) provides us with a consumption-based emissions accounting methodology that considers emission transfers between nations via international trade from 1990-2010; territorial emission inventories are adjusted using estimates of net emission transfers (defined as $\mathrm{CO}_{2}$ emissions in each country minus the emissions in other countries to produce imported goods and services). The consumption-based emission data used in this research use inventories that include $\mathrm{CO}_{2}$ from fossil-fuel combustion, cement production, and gas flaring and do not include emissions from land-use change, such as deforestation. To adjust territorial data for trade, emissions that occur in the supply chain of consumer goods and services are allocated to the appropriate nation based on environmentally extended input-output analysis (see methods section of Peters et al., 2011). Studies suggest that uncertainty is higher for consumption-based emissions compared with territorial emissions (Lenzen, Wood, \& Wiedmann, 2010), however they also indicate that the trends and absolute values are consistent across data, methods, and independent studies (Peters, Davis, \& Andrew, 2012; Wiedmann, Lenzen, Turner, \& Barrett, 2007; Wiedmann, 2009). To remain consistent with the consumption-based emission data-set from Peters et al. (2011), this paper distinguishes developed nations as the countries included in Annex B and the developing and/or underdeveloped nations are classified as the non-Annex B countries to the Kyoto Protocol.

Unlike territorial based emission accounting (that do not take trade into account), consumption-based inventories show that most developed countries have significantly increased their GHG emissions since 1990, despite their Kyoto commitments, through the consumption of goods and services produced in developing nations (Peters et al., 2011). They also result in higher correlations with human development indicators (i.e., life expectancy, income, literacy, \& HDI) when compared to territorial emission accounting (Steinberger et al., 2012). That is, shifting from territorial to consumption-based emissions results in countries moving closer to the regression curve (i.e., the green curve in Figure 1); in general, developed nations (or net importers) move right and many developing countries (net exporters) tend to shift left on the graph (see Figure 1 in Steinberger et al., 2012). The results are useful to understand the distribution of final goods and services as well as the benefit gained by consumers from the embodied emissions of products, both reasons why we employ consumption-based emission data in this research.

One drawback is that trade-corrected inventories do not apportion emissions to the indirect socio-economic gains that may accrue in a nation from product manufacture and export (e.g., employment, technology advancements). For example, the impact of foreign direct investments on the human development of host countries is a popular topic in development studies (e.g., Reiter, 2010; Rodrik, 2006; Sharma \& Gani, 2004). Moreover, development theory and case studies suggest that manufacturing (whether it's driven by foreign investors or domestic efforts) has been the cornerstone of development (especially economic growth) in many nations (e.g., Gereffi, 1989; Hartwick \& Peet, 2009; Anwar, 2008). The implications of this for our results are included the discussion section of this paper. Here, we focus on per capita consumption-based emissions (total emissions attributed to a nation, divided by the population), which approximates the distribution of emissions among individuals within a nation.

\subsection{Human Development Index}

We measure human development in terms of the United Nations Human Development Index (HDI), which provides a composite measure of a nation's income, education and health standards. The HDI is inspired by the capabilities approach to justice, which is a theory of basic human entitlements that provides a standard for determining whether people possess the various capabilities necessary for living a genuinely human life (Sen, 1999a, 1999b; Nussbaum \& Sen, 1992; Nussbaum, 2000, 2006). Using the HDI for measuring human welfare establishes a broader understanding of human well-being (compared with consumption measures alone), which 
is important for climate mitigation policy because it addresses factors that are basic for human life to function and flourish, which will be critical if we are to implement a concept of climate justice that allows for the basic functioning of human communities and the environment (Schlosberg, 2009). All HDI data used in this research were retrieved from the United Nations Development Programme's database (available at http://hdr.undp.org/en/statistics/). The next section outlines the methodology employed to determine a nation's $\mathrm{HDI}$ level, and how the process influences the $\mathrm{CO}_{2} /$ development relationship.

\section{2010 HDI Methodology}

The HDI is inherently complicated by the task of aggregating data in different units and diverse scales of measurement. The HDI dimension of education combines mean years of schooling for adults and expected years of schooling for children (weighted equally), with a range of zero to about twenty years. Also, health is measured by life expectancy at birth with a range of 20 to about 80 years. Lastly, the income dimension is reported in Gross National Income (GNI) per capita PPP\$ (which includes international economic transfers), with a range from $\$ 100$ to $\$ 108,000$. In most cases, the goalposts for each dimension are observed maxima and minima for all countries (Table 1). Before aggregating the data, the HDI uses a rescaling procedure to normalize the indicators to an identical range between zero and one. Both life expectancy and years of schooling are transformed linearly (Equation 1). The income index is normalized differently using a logarithmic transformation (Equation 2). Finally all three indices are aggregated using a geometric mean (Equation 3), assigning equal weight to each dimension (Klugman, Rodrigues, \& Choi, 2011). For a graphical depiction of this normalization procedure, refer to Figure 2.

Table 1. Dimensions, indicators and goalposts used to calculate the 2010 HDI

\begin{tabular}{cccc}
\hline Dimension & Indicator & Observed Maximum & Minimum \\
\hline Health & Life Expectancy & 83.2 & 20 \\
& (years) & (Japan, 2011) & \\
& Mean Years of Schooling & 13.2 & 0 \\
Education & (United States, 2000) & 0 \\
& Expected Years of Schooling & 20.6 & 163 \\
Standard of Living & Per capita income (PPP\$) & (Australia, 2002) & 108,211 \\
& & (United Arab Emirates, 1980) & (Zimbabwe, 2008) \\
\hline
\end{tabular}

$$
\begin{gathered}
\text { Dimensionindex }=\frac{\text { actual value }- \text { minimum value }}{\text { maximum value- minimum value }} \\
\text { Income Index }=\frac{\ln (\text { actualPPP } \$)-\ln (163 P P P \$)}{\ln (108,211 P P P \$)-\ln (163 P P P \$)} \\
H D I=\left(H_{\text {Health }} * H_{\text {Education }} * H_{\text {Living standard }}\right)^{1 / 3}
\end{gathered}
$$

The normalization, weighting, and aggregation inherent to the HDI could distort outcomes (Prado \& Seager, 2011), especially since normative judgments are used to justify procedures (Kovacevic, 2010). For example, the 2010 HDI assigns equal weights to all three dimensions, reflecting the notion that health, education and income are equally important to human development (it is also statistically justified, see Noorbakhsh, 1998). Furthermore, the logarithmic normalization of the income index is based on the assumption that increases in income have a diminishing marginal effect on human well-being (Kovacecic \& Aguna, 2010; Stanton, 2007; Cahill, 2002; Haq, 1999). In other words, the logarithmic transformation reflects the notion that people do not need excessive financial resources to ensure a decent standard of living.

Using a natural logarithm to normalize income is of particular concern for this research, since it produces a saturation-like trend between GNI and per capita $\mathrm{CO}_{2}$ that is not observed before the normalization procedure (see Figure 2(c) and 2(d)). Consequently, countries with GNI levels near the reported minimum see greater returns in HDI than those with high GNI levels for the same income increase. For example, the highest valuation 
of income comes from Zimbabwe (lowest HDI value of 0.140 in 2010), with a 4.1\% increase in HDI for each 1\% increase in income, while Liechtenstein has the lowest income valuation (highest HDI of .938 in 2010), with a $0.05 \%$ increase in HDI for a $1 \%$ increase in income (Kovacevic, 2010). Another significant component of the HDI methodology is the use of a geometric mean (multiplicative aggregation) to combine the dimensions, since it implies diminishing marginal returns in each of the sub-indices and intensifies the diminishing returns of the logarithmic transformation of GNI due to its exponential form (Equation 3) (Klugman et al., 2011).



Figure 2. Graphical depiction of how the 2010 HDI is calculated (HDRP, 2011/01). All graphs contain consumption-based per capita $\mathrm{CO}_{2}$ emissions on the x-axis. Both mean and expected years of schooling (e) are weighted equally and combined using a geometric mean. The orange arrows show the process of normalization, where each data-set is rescaled to a range between zero and one. Life expectancy (a) and combined measures of education (e) are normalized using Equation 1 (results shown in (b) and (f)). GNI (c) is normalized using Equation 2 (result shown in (d)). The red arrows show the aggregation of each dimension via Equation 3 (final result shown in $(\mathrm{g}))$. Data on the development indicators retrieved from United Nations Development Programme, 2010 consumption-based $\mathrm{CO}_{2}$ emissions data provided through personal communication with Dr. Glen Peters.

Therefore, examination of the HDI methodology demonstrates that diminishing returns, especially to the income dimension, are inherent to the HDI calculation. Plus, from Figure 2(a) and 2(e), it is apparent that even before the normalization and aggregation occurs, both life expectancy and measures of education exhibit diminishing returns as per capita $\mathrm{CO}_{2}$ emissions increase by country. This means that the diminishing returns to $\mathrm{HDI}$ is inherent to some of the indicators chosen and not just an artifact of its functional form. However, the question remains how the methodological judgments of the index influence the shape of the resulting saturation-like curve.

\subsection{Sensitivity Analysis}

To bolster the robustness of the HDI functional form and to clarify its influence on determining the diminishing returns relationship observed between gains in human development to increasing $\mathrm{CO}_{2}$ emissions, we conducted our own sensitivity analysis using $2010 \mathrm{HDI}$ and consumption-based $\mathrm{CO}_{2}$ emission data. We are interested in clarifying how the logarithmic transformation of the income dimension and the geometric mean of all 
dimensions influence the observed saturation-like effect shown in Figure 1. We compared the results of the 2010 HDI methodology to other computed versions of the HDI, which lack the logarithmic and exponential qualities that may be enhancing the diminishing returns to HDI.

We computed several test versions of the $2010 \mathrm{HDI}$ and their logarithmic regressions (of the form: $H D I=A^{*} \ln \left(\mathrm{CO}_{2}\right)+B$ ), displayed in Figure 2. HDI 2010 (blue diamonds) is the result of using the $2010 \mathrm{HDI}$ methodology and serves as a point of comparison for the three test versions. Test version HDI 1 (red squares) employs the non-logarithmic normalization formula (Equation 1) for the income dimension, and aggregates with a geometric mean (multiplicative aggregation). Version HDI 2 (green triangles) uses the natural logarithmic function to normalize the income dimension (Equation 2), but employs an arithmetic mean (additive aggregation) to combine the data. The final test version HDI 3 (black crosses) uses a non-logarithmic formula (Equation 1) to normalize the income dimension, and an arithmetic mean to aggregate the three dimensions, this version therefore has no logarithmic or exponential transformations of the data.

\subsection{Sensitivity Results}

As a result of the methodological comparisons in Figure 2, we can infer that the use of the natural logarithmic transformation in the income dimension (HDI 2010 \& HDI 2) results in an upward shift of HDI values, relative to when the non-logarithmic normalization procedure is used for all dimensions (HDI 1 \& HDI 3). Also, the indices with the same aggregation procedures but different normalization methods (e.g., HDI 2010 \& HDI 1) exhibit large differences in HDI values when compared to the indices with same normalization procedures and different aggregation methods (e.g., HDI 2010 \& HDI 2). This suggests that the normalization method (logarithmic or not) has a greater impact on the results than the choice of aggregation. The change in the rate of return of the trend-line is also determined by the version employed, since HDI 3 shows a faster decline in HDI advances than the other versions. Most importantly, all test versions, including HDI 3 that contains no logarithmic or exponential transformations of the data, show diminishing returns, indicating that the saturation-like effect of HDI is not caused by the functional form of the composite index and is an artifact of the indicators included in the index. However the rate of diminishing returns, range of HDI values attained, and potential saturation levels vary depending on the methodology employed.

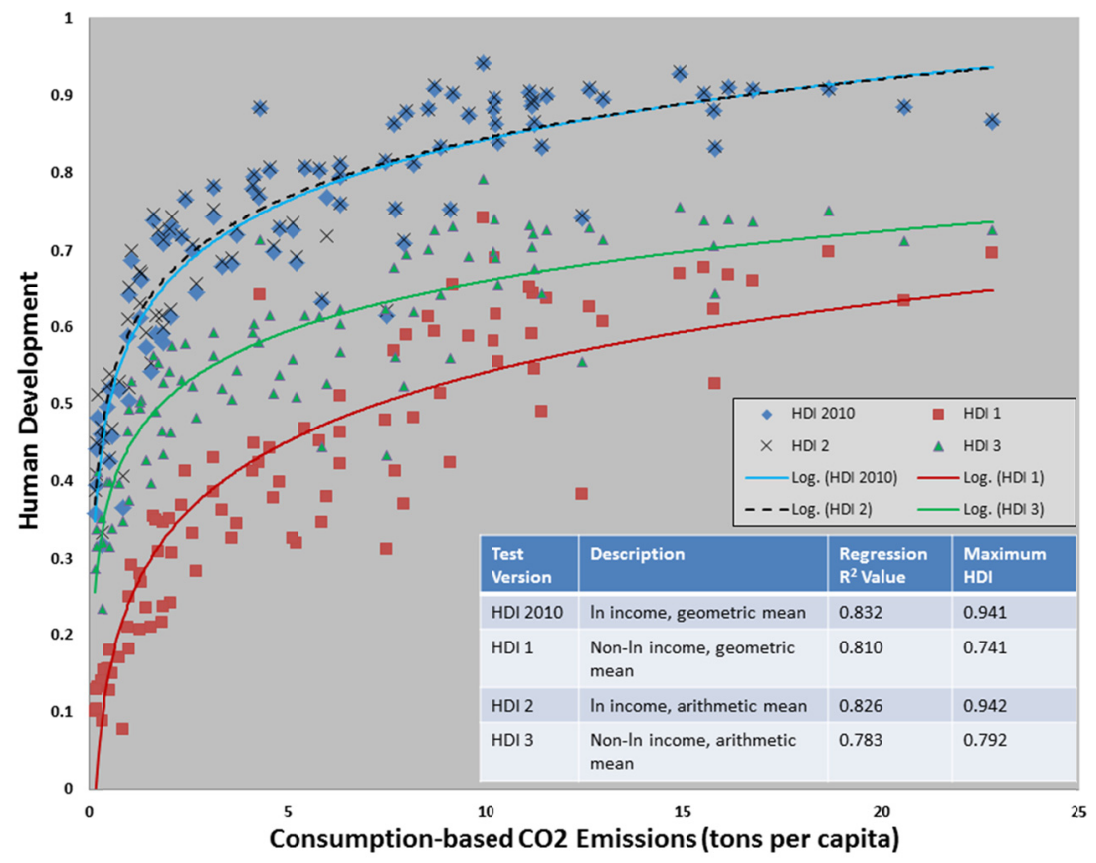

Figure 3. A comparison of the results of the 2010 HDI methodology (blue diamonds) and three other test versions. To quantify the differences between results, the logarithmic regressions (of the form $\left.\mathrm{HDI}=\mathrm{A} * \ln \left(\mathrm{CO}_{2}\right)+\mathrm{B}\right)$ and maximum achieved $\mathrm{HDI}$ are displayed for each version. The $\mathrm{R}^{2}$ values of the regressions are also reported in the table, representing the goodness of fit for each trendline (the closer the $\mathrm{R}^{2}$ value is to 1 , the better the fit) 


\section{Human Development Pathways at the Country Level}

\subsection{Country Level Analysis}

Sustainable climate policy must consider more than global trends in GHG emissions and human development, especially given the diversity in socio-economic aspects, political factors, and climate change impacts across nations (Mendelsohn, 2000; Ostrom, Burger, Field, Norgaard, \& Policansky, 1999; Adger, 2001). That is, an equitable (and likely effective) mitigation system would consider the variability of the $\mathrm{CO}_{2} / \mathrm{HDI}$ relationship among individual nations. To better understand the applicability of the global trend to the country level, we examine the development pathways of individual countries from 1990-2010 (determined by data availability) in terms of their consumption-based $\mathrm{CO}_{2}$ emissions and attained HDI. Although 93 countries were included in Figure 1, three nations (Belarus, Georgia, and Nigeria) did not have adequate historical HDI and consumption-based emissions data to be examined in this part of the study. We constructed graphs of the remaining 90 development pathway at five year-intervals and visually examined them for saturation-like trajectories. Figure $4 \mathrm{a}$ shows the pathways for 24 of the countries studied, selected to show a variety of development levels and pathways. In Figure $4 \mathrm{~b}$ we zoom in on the 14 developing nations whose HDI levels were below 0.5 in 1990 and display trends consistent with the regression ins Figure 1. As expected, very diverse development pathways are exhibited at the country level.

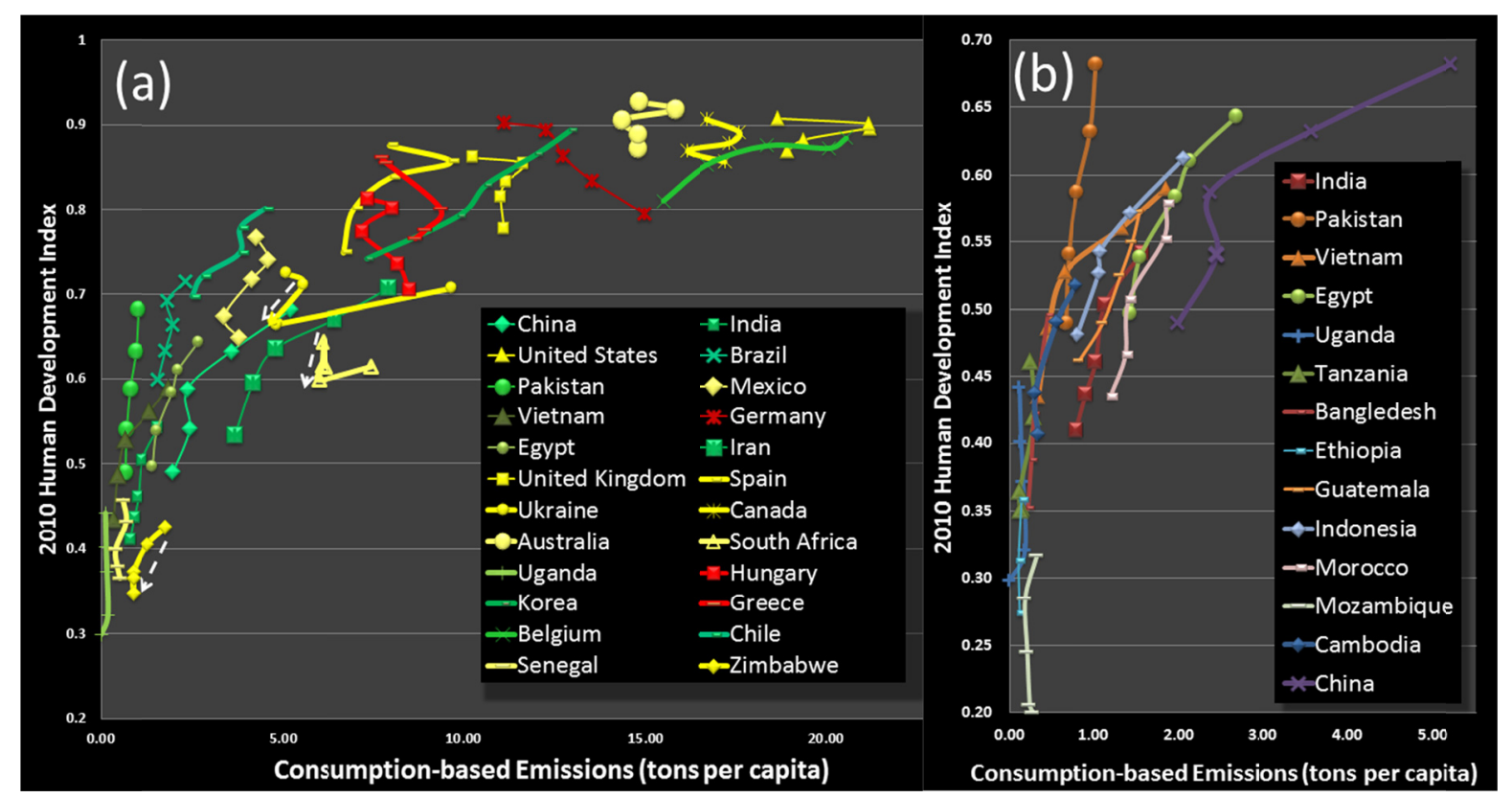

Figure 4. On the left (a), the development pathways of twenty-two countries (out of 90 examined) are displayed showing examples of trajectories at a range of development levels. The pathways are shaded different colors,

depending on the shape of their development trajectory; green pathways are consistent with the global

diminishing returns trend, red pathways undermine the global trend and show alternative trajectories, and pathways in yellow are labeled as inconclusive. On the right (b), we zoom in on fourteen of the world's least developed nations that support our hypothesis, all having $1990 \mathrm{HDI}$ levels below 0.5 . HDI levels are increasing throughout the 1990-2010 period except when the white arrows indicate otherwise

\subsection{Country Level Results}

Nations generally experience increases in HDI throughout the time period, although a small minority did see some declines (e.g., South Africa, Ukraine, Zambia, and Zimbabwe). For this research it is helpful to classify the 90 pathways examined into three categories relative to our original hypothesis, that nations experience diminishing returns to human development as their per capita emissions increase, even at the country level:

(1) Thirty-two of the nations (35.5\%) have pathways that support the hypothesis, by displaying trajectories consistent with a saturation-like trend for the entire 20 year time period). The majority (29/32) of these nations are developing countries, fourteen of which had 1990 HDI levels under 0.5 (Figure 4b). This category includes developing nations, like Uganda and Pakistan, which even today show major growth in 
$\mathrm{HDI}$ for very small increases in $\mathrm{CO}_{2}$, but also developed nations, like Belgium and Singapore, who exhibit very gradual increases in $\mathrm{HDI}$ for large increases in per capita $\mathrm{CO}_{2}$.

(2) Seven of the nations (8\%) undermine the hypothesis, by showing an alternative relationship. For these nations the trend is indirect, where they experience increasing HDI with decreases in $\mathrm{CO}_{2}$ emissions (e.g., red pathways in Figure 4). Five of the pathways belong to Annex I nations (Czech Republic, Germany, Greece, Lithuania, United Kingdom) and six (add Hungary to the group) have 2010 HDI levels over 0.8 . The declines in emissions for these particular nations may be due in part to renewable energy promotion policies like the feed-in tariff and renewable portfolio standard (Lipp, 2007; Martinot, 2007). There are also other drivers of GHG declines in these countries. For example, one study concludes that $60 \%$ of energy related $\mathrm{CO}_{2}$ emission reductions in Germany during the 1990's were due to the restructuring of the East German economy after reunification and the liberalization of energy markets significantly reduced emissions in the UK from 1990-2000 (Eichhammer et al., 2001). Another attributes significant decreases in energy consumption in Hungary to the deterioration of energy intensive industries since 1989 (Szlavik \& Csete, 2012). Madagascar, which remains under 0.5 in HDI, also shows a declining trend in per capita emissions. Although the total emissions have increased in this country overall, the decline we see in per capita emissions is likely attributed to recent population growth, $90 \%$ of which live below the $\$ 2$-a-day extreme poverty level indicator used by the World Bank (Clark, 2012).

(3) Fifty-one of the pathways (56.6\%) are inconclusive, exhibiting periods of development that are consistent with global trends but contain alternative trajectories at other times. These nations show a range of development levels. Out of the 36 Annex I nations examined, 26 of them are in this category. Also, 33 of these nations (64.7\%) have 2010 HDI levels above 0.7 , and 6 countries remain below 0.6 in HDI including Malawi, Zambia and Zimbabwe with 2010 HDI's around 0.4. However, some notable patterns emerge from nations in this category that provide hope for a sustainable energy transition.

Among the large group of nations labeled as 'inconclusive', we found two distinct patterns, particularly among the more developed nations. Ten countries with HDI levels above 0.7 tend to follow an increasing trajectory from 1990-2000, but from 2005-2010 exhibit a sharp decline in $\mathrm{CO}_{2}$ and an increase in HDI (e.g., Australia, U.S., United Kingdom) (Figure 5a). There is also a smaller group of seven nations with HDI levels above 0.6 that show declines in $\mathrm{CO}_{2}$ from 1990-1995, display increasing pathways from about 1995-2005, and another decline in $\mathrm{CO}_{2}$ over the last 5 years of the time period (e.g., Canada, Austria, Switzerland) (Figure 5b). In this latter group, most declines in $\mathrm{CO}_{2}$ are associated with increasing $\mathrm{HDI}$ as well, the exceptions being declines in Estonia and Albania from 1990-1995.

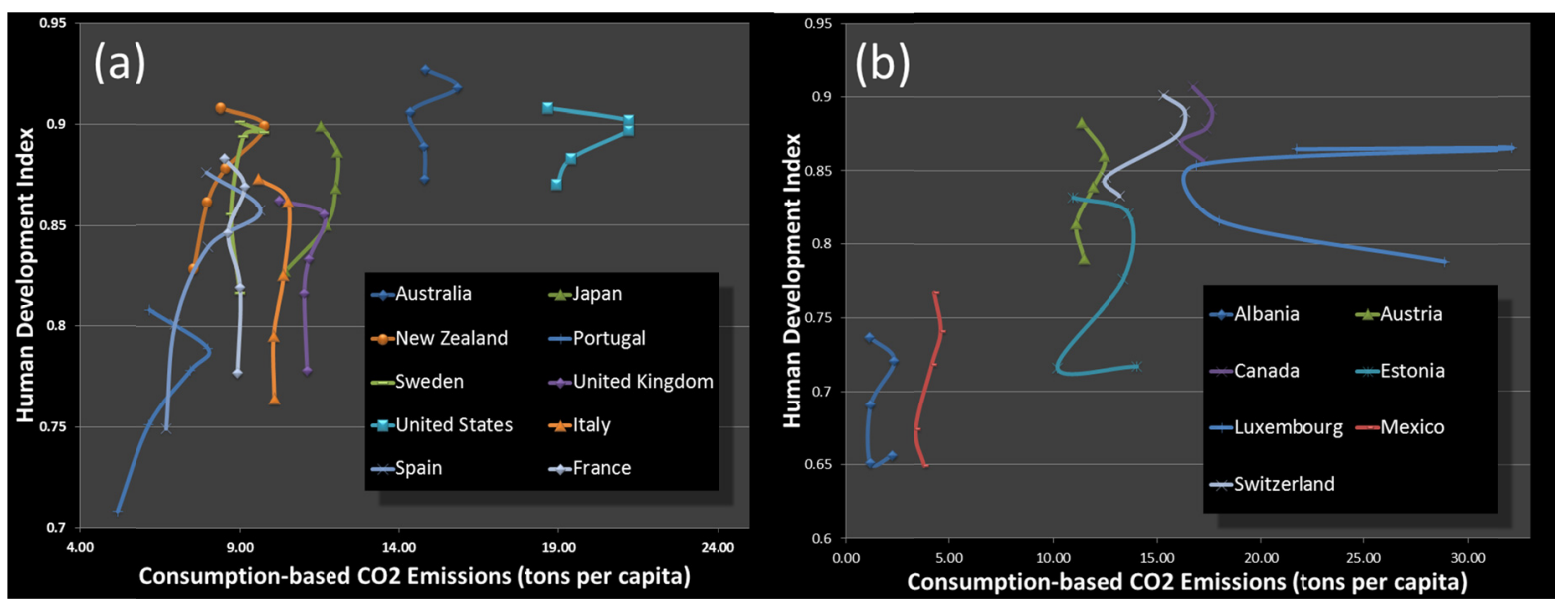

Figure 5. Examples of HDI increases while $\mathrm{CO}_{2}$ declines from 1990-2010. On the left (a) ten developed nations show increasing trajectories from 1990-2005, then a sharp decline in $\mathrm{CO}_{2}$ and an increase in HDI from 2005-2010. On the right (b), seven other countries exhibit the same recent decline in $\mathrm{CO}_{2}$ and increase in $\mathrm{HDI}$, but also display decreases in $\mathrm{CO}_{2}$ from 1990-1995, most of which are associated with increases in HDI 
The patterns of declining $\mathrm{CO}_{2}$ emissions in Figure 5 are evidence of two economic recessions that occurred in the early 1990's and late 2000's. The recession of the early 1990s (associated with the beginning of the Gulf War and resulting spike in oil prices) affected the US economy greatly as well as other economies closely linked with them, such as Canada, Australia, the United Kingdom, as well as Europe and Japan to a lesser degree (McNees, 1992). The more recent recession (associated with the U.S. housing bubble) damaged financial institutions in developed nations around the world (Gore, 2010). In most cases, the declines in $\mathrm{CO}_{2}$ coincide with little to no growth in income, whereas health and education continue to prosper, resulting in an overall increase in HDI for those time periods. This could be good news for climate policy because it is an indication that some developed economies are able to maintain human development improvements despite the potential negative economic impacts of mitigation policies. Of course, our analysis does not tell us anything about the long term ability of these nations to withstand economic declines without sacrifices in health and education.

\section{Discussion}

According to the consumption-based emission data we employ in this research, a typical American emits just under 19 tons of $\mathrm{CO}_{2}$ a year, which is about 12 times that of an average Indian and 60 times that of an average individual living in Mozambique. This research shows that the HDI level attained at these wide ranges of emissions is driven by both the indicators chosen and how the indicators are aggregated. In terms of income, education, and health indicators it is clear that industrialized nations are emitting far more $\mathrm{CO}_{2}$ than necessary to maintain high levels of human well-being. The HDI sensitivity analysis shows that neither the method of normalization or aggregation actually causes the diminishing returns to $\mathrm{HDI}$ from $\mathrm{CO}_{2}$ emissions, but does influence the rate of return, the range of HDI values attained by nations, as well as the saturation level of the data regression curves. Bearing this mind, the HDI is particularly valuable for country comparisons and ranking (Kovacecic \& Aguna, 2010) but less appropriate for specific climate policy design. That is, Figure 1 is helpful to show the relative achievements of nations at various levels of $\mathrm{CO}_{2}$ emissions, and thus useful in determining which nations are being more efficient with their emissions than others in terms of human development, but it should not be the sole basis for assigning emission reduction targets to individual nations.

The country-level investigation finds that a little over a third of the nations we examined have pathways from 1990-2010 consistent with the global 2010 trend (shown in Figure 1), and a small minority display alternative trajectories during that time. This means that over half the nations exhibit more complex development pathways (many of them developed nations) than our hypothesis suggests, a portion of which can be explained by declines in per capita $\mathrm{CO}_{2}$ emissions and income during two economic recessions (see Figure 5). That leaves about one third of nations whose development pathways differ from the aforementioned patterns, indicating that a generalizable model of development for all nations is non-existent.

Nevertheless, this analysis does reveal important findings for designing future climate policy. Although developed nations generally do not display consistent development trends at the country level, most reveal times when their HDI levels continue to increase while their per capita $\mathrm{CO}_{2}$ emissions decrease. We see this most clearly among developed nations during times of economic recessions (Figure 5). These declines in $\mathrm{CO}_{2}$ are typically reflected in little to no growth in the income dimension of the HDI, whereas life expectancy and years of schooling typically continue to rise, resulting in an overall higher HDI level. However, given the relatively short time period examined here, the sustainability of these non-income parameters in unknown. Regardless, if policy-makers use income as the sole proxy for human development, it is clear that mitigation efforts become equated with a lower quality of life, which reduces the likelihood of mitigation support. However, if development is viewed in a broader sense, as in the HDI, mitigation doesn't necessarily mean sacrifices to a person's overall well-being. The challenge is then to shift the focus of development away from material consumption and more towards less GHG intensive goals, such as quality of education and healthier lifestyles. Simultaneously, the challenge of further decoupling energy from carbon needs to be addressed, in which renewable energy technology development will likely play a significant role.

On the other hand, when we zoom in on the pathways of the least developed nations (such as those with 1990 HDI levels under 0.5; some of which are displayed in Figure 4b), they overwhelmingly show large gains in HDI from little to no increases in consumption-based $\mathrm{CO}_{2}$ emissions. The instances where developing nations do experience HDI increases with no increase in $\mathrm{CO}_{2}$ (or even declines in $\mathrm{CO}_{2}$ ) could be the result of rapid population increases during the time period or may be a result of nations that primarily manufacture goods and services for export and consumption elsewhere. As mentioned previously, domestic manufacturing, even if the products are consumed elsewhere (meaning that the emissions would be allocated to another country), can lead to local human development improvements in the form of jobs and wages which under the right circumstances may also lead to health and education improvements (e.g., Heintz, 2007; Chudnovsky \& Lopez, 2002; Reiter, 
2010). Nevertheless, the fact that fourteen of the nations examined display consistent upward trends in HDI as their per capita $\mathrm{CO}_{2}$ emissions increase indicates that under current technology constraints, $\mathrm{CO}_{2}$ emissions are likely a co-requisite for human development improvements within the least developed nations of the world.

Moreover, our findings inform discussions of equitable $\mathrm{CO}_{2}$ distributions in the context of sustainable policy design. On the one hand, some propose that carbon emissions should be allocated on an equal per capita basis (e.g., Singer, 2004; Jamieson, 2005). Alternatively, others appeal to the fact that emissions play very different roles in people's lives and therefore emission rights should be allocated in a way that those differences are reflected (Shue, 1993; Lomborg, 2001). For example, Shue (1993) points out the differences between what he calls 'subsistence' and 'luxury' emissions and argues that it would be unjust to ask individuals to surrender necessities so that others can retain luxuries. Our analysis supports the latter, since, $\mathrm{CO}_{2}$ is found to play a significant role in the ability of developing countries to achieve improvements in HDI, yet not always necessary to improve HDI levels within developed nations.

Furthermore, the fact that underdeveloped nations experience significant gains in HDI from relatively small increases in per capita emissions suggests that under a system of global mitigation, emission rights should be allocated towards (and not away from) these nations. Typically, market-based approaches to mitigation seek the opposite by allocating emissions in a way that optimizes profitability (i.e., maximizes GDP per unit of emission). Consequently, emission rights are allocated to the richest and most developed nations. Alternatively, if climate policies were framed to optimize advances in human development per unit of emission, the policy structure would protect the emission rights of the least developed nations, while enforcing emission reductions on the already sufficiently developed nations. Although the details of Kyoto's predecessor have yet to be determined, country leaders are currently discussing a "universal, legally binding international agreement" under which all major emitters would contribute to the mitigation effort at some level (UNEP, 2012). Our findings suggest that emission reductions or limits placed on developing nations (especially in the 14 nations identified in Figure $4 \mathrm{~b}$ ) would likely inhibit necessary human development improvements (such as access to modern energy sources) within those nations. This result would be in direct opposition of the United Nation's definition of sustainable development (1987), since it would take priority away from fulfilling the essential needs the world's poor.

\section{Acknowledgements}

This material is based upon work supported by the National Science Foundation under Grant No. 1134943. The Global Institute of Sustainability at Arizona State University and the Arizona Board of Regents also provided support. We would like to thank Sonja Klinsky and Brad Allenby for their helpful comments in preparing this manuscript.

\section{References}

Adger, W. N. (2001). Scales of Governance and Environmental Justice for Adaptation and Mitigation of Climate Change. Journal of International Development, 13, 921-931. http://dx.doi.org/10.1002/jid.833

Anand, S., \& Sen, A. (2000). The Income Component of the Human Development Index. Journal of Human Development, 1(1), 83-106. http://dx.doi.org/10.1080/14649880050008782

Anwar, S. (2008). Foreign investment, human capital and manufacturing sector growth in Singapore. Journal of Policy Modeling, 30(3), 447-453. http://dx.doi.org/10.1016/j.jpolmod.2007.12.008

Ayres, R., \& Ayres, E. (2010). Crossing the Energy Divide: Moving from Fossil Fuel Dependence to a Clean-Energy Future. New Jersey: Prentice Hall. ISBN: 7980137015443

Barker, T., Bashmakov, I., Bernstein, L., Bogner, J. E., Bosch, P. R., Dave, R., ... Zhou, D. (2007). Technical Summary. In B. Metz, O. R. Davidson, P. R. Bosch, R. Dave, \& L. A. Meyer (Eds). Climate Change 2007: Mitigation. Contribution of Working Group III to the Fourth Assessment Report of the Intergovernmental Panel on Climate Change. Cambridge, United Kingdom and New York, NY, USA: Cambridge University Press. Retrieved from http://www.ipcc.ch/publications_and_data/ar4/wg 3/en/ts.html

Beg, N., Morlot, J. C., Davidson, O., Afrane-Okesse, Y., Tyani, L., Denton, F., Sokona, Y., ... Rahman, A. A. (2002). Linkages between climate change and sustainable development. Climate Policy, 2, 129-144. http://dx.doi.org/10.3763/cpol.2002.0216

Birol, F. (2007). Energy Economics: A Place for Energy Poverty in the Agenda. The Energy Journal, 28(3), 1-6. http://dx.doi.org/10.5547/ISSN0195-6574-EJ-Vol28-No3-1

Cahill, M. (2002). Diminishing returns to GDP and the Human Development Index. Applied Economics Letters, 9, 885- 887. http://dx.doi.org/10.1080/13504850210158999 
Chudnovsky, D., \& Lopez, A. (2002). Globalization and Developing Countries: Foreign Direct Investment, Growth and Sustainable Human Development, UNCTAD Occasional Paper. Retrieved from http://www.tci-network.org/media/asset_publics/resources/000/000/788/original/globalization-chudnovsky. pdf

Clark, M. (2012). Deforestation in Madagascar: Consequences of Population Growth and Unsustainable Agricultural Processes. Global Majority E-Journal, 3(1), 61-71. Retrieved from http://www.american.edu/cas/economics/ejournal/upload/Global_Majority_e_Journal_3_1.pdf

Eichhammer, W., Boede, U., Gagelmann, F., Jochem, E., Kling, N., Schleich, J., Schlomann, B., ... Ziesing, H. J. (2001). Greenhouse gas reductions in Germany and the UK-Coincidence or policy induced. Fraunhofer Institute for Systems and Innovation Research, Karlsruhe. Retrieved from http://www.isi.fraunhofer.de/isi-media/docs/x/de/publikationen/wallfall/co2report-isi-e-final.pdf

Gerreffi, G. (1989). Rethinking Development Theory: Insights from East Asia and Latin America. Sociological Forum, 4(4), 505-533. Retrieved from http://www.jstor.org/stable/684423

Gore, C. (2010). The global recession of 2009 in a long-term development perspective. Journal of International Development, 22(6), 714-738. http://dx.doi.org/10.1002/jid.1725

Haq, U. (1999). Reflections on Human Development. Oxford: CUP. ISBN: 9780195101935

Hartwick, E., \& Peet, R. (2009). Theories of Development: Contentions, Arguments, Alternatives. New York, NY: Guilford Publications. PMid:18757519

Heintz, J. (2007). Human Development and Clothing Manufacturing in Cambodia: Challenges and Strategies for the Garment Industry. Political Economy Research Institute. Retrieved from http://wiego.org/sites/wiego.org/files/publications/files/Heintz-Cambodia-Garment-Report.pdf

IPCC. (2008). 2006 IPCC Guidelines for National Greenhouse Gas Inventories - A primer, Prepared by the National Greenhouse Gas Inventories Programme. In H. S. Eggleston, K. Miwa, N. Srivastava, \& K. Tanabe (Eds). Published: IGES, Japan. Retrieved from http://www.ipcc-nggip.iges.or.jp/public/2006gl/index.html

Jamieson, D. (2005). Adaptation, Mitigation, and Justice. Advances in the Economics of Environmental Resources, 5, 217-248. http://dx.doi.org/10.1016/S1569-3740(05)05010-8

Klugman, J., Rodriguez, F., \& Choi, H. J. (2011). Human Development Research Paper 2011/01: The HDI 2010: New Controversies, Old Critiques. Retrieved from http://hdr.undp.org/en/reports/global/hdr2011/papers/HDRP_2011_01.pdf

Kovacevic, M. (2010). Review of HDI Critiques and Potential Improvements. United Nations Development Programme. Retrieved from http://hdr.undp.org/en/reports/global/hdr2010/papers/HDRP_2010_33.pdf

Kovacevic, M., \& Aguna, C. G. (2010). Uncertainty and Sensitivity Analysis of the Human Development Index 2010. United Nations Development Programme. Retrieved from http://hdr.undp.org/en/reports/global/hdr2010/papers/HDRP_2010_47.pdf

Lenzen, M., Wood, R., \& Wiedmann, T. (2010). Uncertainty analysis for Multi-Region Input-Output Models-A case study of the UK's carbon footprint. Econ. Syst. Res., 22, 43-63. http://dx.doi.org/10.1080/09535311003661226

Le Quéré, C., Raupach, M. R., Canadell, J. G., Marland, B. L., Ciaia, P., .. Woodward, F. I. (2009). Trends in the sources and sinks of carbon dioxide. Nature Geoscience, 2, 831-836. http://dx.doi.org/10.1038/ngeo689

Lipp, J. (2007). Lessons for effective renewable electricity policy from Denmark, Germany and the United Kingdom. Energy Policy, 35(11), 5481-5495. http://dx.doi.org/10.1016/j.enpol.2007.05.015

Lomborg, B. (2001). Global Warming. In B. Lomborg (Ed.), The Skeptical Environmentalist (pp. 258-324). Cambridge: Cambridge University Press. ISBN-13: 978-0521010689

Martínez, D. M., \& Ebenhack, B. W. (2008). Understanding the role of energy consumption in human development through the use of saturation phenomena. Energy Policy, 36, 1430-1435. http://dx.doi.org/10.1016/j.enpol.2007.12.016

Martinot, E. (2007). Renewables 2007 Global Status Report. Renewable Energy Policy Network. Retrieved from http://www.martinot.info/RE2007_Global_Status_Report.pdf

McNees, S. (1992). The 1990-91 Recession in Historical Perspective. Board of Governors of the Federal Reserve System. Retrieved from http://www.bos.frb.org/economic/neer/neer1992/neer192a.pdf 
Mechtenberg, A., Borchers, K., Miyingo, E. W., Hormasji, F., Hariharan, A., Makanda, J. V., \& Musaazi, M. K. (2012). Human power (HP) as a viable electricity portfolio option below 20 W/Capita. Energy for Sustainable Development, 16, 125-145. http://dx.doi.org/10.1016/j.esd.2011.12.006

Mendelsohn, R., Morrison, W., Schlesinger, M. E., \& Andronova, N. G. (2000). Country Specific Market Impacts of Climate Change. Climate Change, 45(3-4), 553-569. http://dx.doi.org/10.1023/A:1005598717174

Moran, D. D., Wackernagel, M., Kitzes, J. A., Goldfinger, S. H., \& Boutaud, A. (2008). Measuring sustainable development - nation by nation. Ecological Economics, 64(3), 470-474. http://dx.doi.org/10.1016/j.ecolecon.2007.08.017

Noorbakhsh, F. (1998). The Human Development Index: Some Technical Issues and Alternative Indices. Journal of International Development, 10(5), 589-605. http://dx.doi.org/10.1002/(SICI)1099-1328(199807/08)10:5<589::AID-JID484>3.0.CO;2-S

Nussbaum, M. (2000). Women and Human Development: The Capabilities Approach. Cambridge: Cambridge University Press. http://dx.doi.org/10.1017/CBO9780511841286

Nussbaum, M. (2006). Frontiers of Justice: Disability, Nationality, Species Membership, Cambridge, MA: Harvard University Press. ISBN 9780674024106

Nussbaum, M., \& Sen, A. (1992). The Quality of Life, Oxford: Oxford University Press. ISBN 9780198287971.

O’Brien, K., \& Leichenko, R. (2006). Climate Change, Equity and Human Security. Die Erde, 137(3), 223-240.

Ostrom, E., Burger, J., Field, R. B., Norgaard, R. B., \& Policansky, D. (1999). Revisting the Commons. Science, 284(5412), 278-282. http://dx.doi.org/10.1126/science.284.5412.278

Pasternak, A. D. (2000). Global Energy Futures and Human Development: a framework for analysis. US Department of Energy, Oak Ridge.

Peters, G. P., \& Hertwich, E. G. (2008). $\mathrm{CO}_{2}$ embodied in international trade with implications for global climate policy. Environmental Science \& Technology, 42(5), 1401-1407. http://dx.doi.org/10.1021/es072023k

Peters, G. P., Minx, J. C., Weber, C., \& Edenhofer, O. (2011). Growth in emission transfers via international trade from 1990-2008. PNAS, 108(21), 8903-8908. http://dx.doi.org/10.1073/pnas.1006388108

Peters, G. P., Davis, S. J., \& Andrew, R. (2012). A synthesis of carbon in international trade. Biogiosciences, 9 , 3247-3276. http://dx.doi.org/10.5194/bg-9-3247-2012

Prado, V., Rogers, K., \& Seager, T. P. (2012). Integration of MCDA Tools in Valuation of Comparative Life Cycle Assessment. In M. A. Curran (Ed.), Life Cycle Assessment Handbook: A guide to Environmentally Sustainable Products (Part 3, Chapter 19). http://dx.doi.org/10.1002/9781118528372.ch19

Reiter, S. L. (2010). Human Development and Foreign Direct Investment in Developing Countries: The Influence of FDI Policy and Corruption. World Development, 38(12), 1678-1691. http://dx.doi.org/10.1016/j.worlddev.2010.04.005

Rodrik, D. (2006). What's So Special about China's Exports? China \& World Economy, 14(5), 1-19. http://dx.doi.org/10.1111/j.1749-124X.2006.00038.x

Sen, A. (1999a). Commodities and Capabilities. Oxford: Oxford University Press.

Sen, A. (1999b). Development as Freedom. New York: Anchor.

Schlosberg, D. (2009). Climate Justice, the Capabilities Approach, and Potential Policy Implications. Prepared for presentation at the final seminar in the series on The EU, Climate Change, and Global Environmental Governance, University of Edinburgh.

Sharma, B., \& Gani, A. (2004). The Effects of Foreign Direct Investment on Human Development. Global Economy Journal, 4(2), Article 9. http://dx.doi.org/10.2202/1524-5861.1049

Shue, H. (1993). Subsistence Emissions and Luxury Emissions. Law \& Policy, 15(1), 39-60. http://dx.doi.org/10.1111/j.1467-9930.1993.tb00093.x

Singer, P. (2004). One Atmosphere. In P. Singer (Ed.), One World: The Ethics of Globalization. New Haven, CT: Yale University Press.

Stanton, E. A. (2007). The Human Development Index: A History, Political Economy Research Institute. UMass Amherst, Working paper series no. 127. Retrieved from 
http://www.peri.umass.edu/fileadmin/pdf/working_papers/working_papers_101-150/WP127.pdf

Steinberger, J., \& Roberts T. (2010). From constraint to sufficiency: The decoupling of energy and carbon from human needs, 1975-2005. Ecological Economics, http://dx.doi.org/10.1016/j.ecolecon.2010.09.014

Steinberger, J., Roberts, T., Peters, G., \& Baiocchi, G. (2012). Pathways of human development and carbon emissions embodied in trade. Nature Climate Change. http://dx.doi.org/10.1038/nclimate1371

Suarez, C. E. (1995). Energy needs for sustainable human development. In J. Goldemberg, \& T. B. Johansson (Eds.), Energy as an Instrument for Socio-Economic Development. New York United Nations Development Programme.

Swart, R., Robinson, J., \& Cohen, S. (2003). Climate change and sustainable development: expanding the options. Climate Policy, 3S1, S19-S40. http://dx.doi.org/10.1016/j.clipol.2003.10.010

Szlavik, J., \& Csete, M. (2012). Climate and Energy Policy in Hungary. Energies, 5, 494-517. http://dx.doi.org/10.3390/en5020494

Tol, R. (2009). The Economic Effects of Climate Change. Journal of Economic Perspectives, 23(2), 29-51. http://dx.doi.org/10.1257/jep.23.2.29

United Nations. (1987). United Nations Report of the World Comission on Environment and Development, Our Common Future: Brundtland Report. Retrieved from http://www.worldinbalance.net/intagreements/1987-brundtland.php

United Nations Development Programme (UNDP). (2007). Human Development Report 2007/2008, Fighting climate change: Human solidarity in a divided world. New York, NY: Palgrave Macmillan. Retrieved from http://hdr.undp.org/en/reports/global/hdr2007-8/

United Nations Development Programme (UNDP). (2011). International Human Development Indicators. Retrieved from http://hdr.undp.org/en/statistics/hdi/

United Nations Environment Programme. (2012). Doha Climate Conference Opens Gateway to Greater Ambition and Action on Climate Change. UNEP News Centre Retrieved from http://www.unep.org/newscentre/default.aspx?DocumentID=2700\&ArticleID=9353

Wiedmann, T. (2009). A review of recent multi-region input-output models used for consumption-based emissions and resource accounting. Ecol. Econ., 69, 211-222. http://dx.doi.org/10.1016/j.ecolecon.2009.08.026

Wiedmann, T., Lenzen, M., Turner, K., \& Barrett, J, (2007). Examining the global environmental impact of regional consumption activities-Part 2: Review of input output models for the assessment of environmental impacts embodied in trade. Ecol. Econ., 61, 15-26. http://dx.doi.org/10.1016/j.ecolecon.2006.12.003

World Bank. (2011). World Development Indicators. Retrieved February 18, 2013, from http://databank.worldbank.org/ddp/home.do 